\title{
Cirrus Cloud Macrophysical and Optical Properties over North China from CALIOP Measurements
}

\author{
MIN Min*广1 (闵 敏), WANG Pucai ${ }^{1}$ (王普才), James R. CAMPBELL ${ }^{2}$, \\ ZONG Xuemei ${ }^{1}$ (宗雪梅), and XIA Junrong ${ }^{1}$ (夏俊荣) \\ ${ }^{1}$ Key Laboratory of Middle Atmosphere and Global Environment Observation, \\ Institute of Atmospheric Physics, Chinese Academy of Sciences, Beijing 100029 \\ ${ }^{2}$ UCAR Visiting Scientist Programs, Naval Research Laboratory, Monterey, California, USA
}

(Received 16 March 2010; revised 21 June 2010)

\begin{abstract}
Two years of mid-latitude cirrus cloud macrophysical and optical properties over North China are described from Earth-orbiting Cloud-Aerosol Lidar with Orthogonal Polarization (CALIOP) satellite measurements. Global cloud climatological studies based on active remote sensing data sets benefit from more accurate resolution of vertical structure and more reliable detection of optically thin layers. The mean values for cirrus cases over North China are $0.19 \pm 0.18$ for infrared emittance, $0.41 \pm 0.68$ for visible optical depth $0.26 \pm 0.12$ for integrated depolarization ratio, and $0.72 \pm 0.22$ for integrated color ratio. When studied using reasonable assumptions for the relationship between extinction and ice crystal backscatter coefficients, our results show that most of the cirrus clouds profiled using the $0.532 \mu \mathrm{m}$ channel data stream correspond with an optical depth of less than 1.0. The dependence of cirrus cloud properties on cirrus cloud mid-cloud temperature and geometry thickness are generally similar to the results derived from the ground-based lidar, which are mainly impacted by the adiabatic process on the ice cloud content. However, the differences in macrophysical parameter variability indicate the limits of spaceborne-lidar and dissimilarities in regional climate variability and the nature and source of cloud nuclei in different geographical regions.
\end{abstract}

Key words: cirrus cloud, spaceborne-lidar, optical depth

Citation: Min, M., P. C. Wang, J. R. Campbell, X. M. Zong, and J. R. Xia, 2011: Cirrus cloud macrophysical and optical properties over North China from CALIOP measurements. Adv. Atmos. Sci., 28(3), 653-664, doi: 10.1007/s00376-010-0049-5.

\section{Introduction}

Instantaneous global cloud cover is approximately $70 \%$, meaning that clouds significantly influence the atmospheric hydrological cycle and radiation budget of the Earth climate system (Baker, 1997; Lynch et al., 2002; Sassen et al., 1989; Wielicki et al., 1995). Cirrus clouds, consisting predominantly of non-spherical ice crystals, are distinct in the visible sky. They are often optically thin and persist in unique macrophysical shapes and forms. This is due to the turbulent and sheared wind flow characteristic of the uppertroposphere where they are most frequently found.
Earlier estimates of global cirrus cloud cover were 20\%-35\% (Heymsfield, 1975; Liou, 1986). With the benefit of improved global observation networks and retrieval techniques, more current estimates place this value closer to 40\% (Wylie et al., 1994; Wylie and Menzel, 1999; Sassen and Wang, 2008).

An important difference between cirrus clouds and other hydrometeor layers is that they may exhibit dual/opposing characteristics when considering their role in the radiative balance of the atmosphere. Small ice crystals $(<1.0 \mu \mathrm{m})$ induce relatively high albedos, as incoming solar radiation is more efficiently reflected back to space. However, more commonly, cirrus lay-

\footnotetext{
*Corresponding author: MIN Min, minmin@cma.gov.cn

${ }^{\dagger}$ Current affiliation: Key Laboratory of Radiometric Calibration and Validation for Environmental Satellites, China Meteorological Administration (LRCVES/CMA), National Satellite Meteorological Center, China Meteorological Administration, Beijing 100081

(C) China National Committee for International Association of Meteorology and Atmospheric Sciences (IAMAS), Institute of Atmospheric Physics (IAP) and Science Press and Springer-Verlag Berlin Heidelberg 2011
} 
ers absorb infrared radiation emitted by the planetary surface and, therefore, act as greenhouse components to cause warming of the equilibrium climate, particularly in the Tropics (Liou, 1986; IPCC, 2007). Simulations (Takano and Liou, 1989a, b) indicate that the climatic impact of cirrus clouds can be characterized by their radiative properties, which are, in turn, related to physical properties that include cloud heights, temperatures, and the shape and orientation of ice crystals (Sassen et al., 1989; Stephens et al., 1990). Global variability is considered very likely, as these many characteristics are influenced by the regional climate (Sassen and Campbell, 2001). Therefore, parameterizations for cirrus cloud physical processes in numerical models must be investigated and reported from many representative regimes, as they are necessary to decrease fundamental uncertainties in climate prediction (Martin et al., 1988).

Many sophisticated ground-based and spaceborne techniques (Platt, 1973; Sassen, 1991; Winker and Trepte, 1998) have been developed to observe cirrus clouds. A ground-based lidar-radiometer (LIRAD) method developed by Platt (1973), with some extensions by Young (1995), has been extensively used to determine cloud radiative and optical properties (Platt, 1979; Platt et al., 1998, 2002a, b). The CloudAerosol and Infrared Pathfinder Satellite Observations (CALIPSO) satellite was launched (Winker et al., 2003) in June 2006 as a component of the U.S. National Aeronautics and Space Administration (NASA) Afternoon Constellation (Stephens et al., 2002), or "A-Train". Its primary payload, the Cloud-Aerosol Lidar with Orthogonal Polarization (CALIOP) is designed to provide global vertical profiling information of clouds and aerosols. Since cirrus clouds often exist as part of a multilayered cloud system, and are characteristically optically thin and physically high, they are difficult to study from passive satellite radiance measurements and accurately resolve from scattered ground observing sites. Therefore, the CALIOP instrument offers an opportunity to characterize cirrus cloud properties globally (Winker et al., 2007, 2009). The CALIOP instrument is a dual wavelength $(0.532$ and $1.064 \mu \mathrm{m})$, polarization-sensitive backscatter lidar. The CALIPSO satellite, however, also serves as a platform for a passive Imaging Infrared Radiometer (IIR) and a Wide Field Camera (WFC) (Winker et al., 2009). Synergy of these nadir-viewing sensors allows for a complete representation of physical cirrus cloud properties. The high quality of processed CALIPSO data products has been demonstrated through validation campaigns (McGill et al., 2007; Winker et al., 2007; Vaughan et al., 2008; Kahn et al., 2008; Kim et al., 2008).
Previous observations on mid-latitude cirrus cloud properties using ground-based instruments (Platt, 1979; Sassen and Campbell, 2001; Immler and Schrems, 2002a) have been conducted at many sites worldwide. However, it is apparent that many gaps exist in our understanding of spatial variability. In the current investigation, we focus on the mid-latitude cirrus cloud properties observed over North China using CALIOP (a domain bracketed from $35^{\circ} \mathrm{N}$ to $45^{\circ} \mathrm{N}$ and $110^{\circ} \mathrm{E}$ to $120^{\circ} \mathrm{E}$ ). We believe this to be the first such study completed for this eastern Asia region. In order to determine the regional quality of climatological cirrus cloud properties, these observations are compared with ground-based studies reported previously from other regions. The paper is organized as follows: a brief introduction to the CALIOP data, and an introduction to the methodology of retrieving infrared and visible optical properties of cirrus clouds, are presented in section 2 ; section 3 describes and discusses the results of macrophysical, infrared optical, visible optical, depolarization ratio, and color ratio properties; finally, the major results are summarized in section 4 .

\section{Data and methodology}

\section{$2.1 \quad$ Data}

We have studied two years (June 2006-May 2008) of CALIOP measurements of cirrus clouds over North China. Value-added project data sets are distributed online (http://eosweb.larc.nasa.gov/PRODOCS/calipso/table_calipso.html). The Level 1B infrared radiance (IR) data (CAL_IIR L1-Pro-V1-10) at three wavelengths $(8.65,10.6$, and $12.05 \mu \mathrm{m})$ are used to calculate infrared cloud properties. Level 2 cloud layer products at $5 \mathrm{~km}$ horizontal resolution (CAL_LID_ L2_05 kmCLay-Prov-V2-01) are used to characterize cirrus clouds macrophysical and optical properties. The CALIOP level 2 feature mask (Liu et al., 2009; Vaughan et al., 2009) is used to identify cirrus clouds (Liu et al., 2005; Hu et al., 2009). In addition to the infrared properties, other physical and optical properties of cirrus cloud are derived from Level 2 cloud layer products.

In light of the distinguishable properties of midlatitude cirrus clouds summarized by previous research, we consider three supplemental criteria to discriminate cirrus clouds in these processed data products in order to limit the potential of false identification biasing of the North China sub-sample. The first ensures a minimum cloud base height of $5 \mathrm{~km}$ (Dowling and Radke, 1990). The second and third restrict the maximum cloud top height temperature to $-40^{\circ} \mathrm{C}$ and the maximum visible optical depth to 3.0 (Sassen and Cho, 1992; Sassen and Campbell, 2001), respec- 
tively. Several important additional parameters relating to cirrus cloud observations are included in these CALIOP data product files. These include cirrus cloud visible optical depth, cloud top and base heights, geometric thickness and thermodynamic profiles derived by the NASA Global Modeling and Assimilation Office (GMAO) (Winker et al., 2009).

\section{$2.2 \quad$ Methodology}

\subsubsection{Infrared optical properties}

Infrared radiance products from IIR are used to calculate the thermal infrared emittance $\varepsilon_{\mathrm{a}}$. The calibrated infrared radiance $L_{\mathrm{m}}$ at the top of the atmosphere for the three sampled wavelengths can be written as follows (Chomette et al., 2003; Platt and Young, 2004):

$$
L_{\mathrm{m}}=\varepsilon_{\mathrm{a}} L_{\mathrm{B}}\left(T_{\mathrm{mid}}\right)+\left(1-\varepsilon_{\mathrm{a}}\right) L_{\mathrm{a}},
$$

where $L_{B}$ is the IR spectral blackbody radiance at mid-cloud temperature $T_{\text {mid }}$ calculated using Planck's formula in which $L_{\mathrm{a}}$ is the vertical upward background infrared radiance at the top of the atmosphere in the cloudless region. A new and simple approach is offered here to compute the upward $L_{\mathrm{a}}$, which uses the averaged values in the cloudless regions near the cirrus height within a range of 2.0 latitudinal degrees as $L_{\text {a }}$. This is based on the assumption of neglecting atmospheric infrared radiance above cirrus clouds because it is assumed that all the water vapor resides below the clouds (Platt, 1979; Platt et al., 2002a). In addition, due to the relatively low magnitudes of the reflecting and scattering infrared radiances at the bottom of the cirrus, both of them are neglected in Eq. (1) (Platt, 1979; Platt et al., 1998). However, no retrievals are performed if there is no spatial interval without clouds along the CALIOP scanning paths or the existence of multilayer cirrus cloud structure.

\subsubsection{Visible Optical Properties}

For a cirrus cloud at range $r$ from the CALIOP instrument, the measured lidar signal power can be written as:

$$
P(r)=\frac{C}{r^{2}}\left[\beta_{\mathrm{m}}(r)+\beta_{\mathrm{c}}(r)\right] T_{\mathrm{m}}^{2}(0, r) T_{\mathrm{c}}^{2}\left(r_{\mathrm{t}}, r\right)+P_{\mathrm{o}},
$$

where $C$ is a lidar system constant that includes output energy, $r_{\mathrm{t}}$ represents the range of the cloud top (as CALIOP is nadir-viewing), $\beta_{\mathrm{m}}(r)$ and $\beta_{\mathrm{c}}(r)$ are the molecular and cloud backscatter coefficients, $T_{\mathrm{m}}$ and $T_{\mathrm{c}}$ are the molecular and cloud transmittance, and $P_{\mathrm{o}}$ is the background signal power (Young, 1995; Young and Vaughan, 2009).

Previous studies show that the cloud transmittance method (Young, 1995; Chen et al., 2002) can retrieve cirrus visible optical depth, $\delta_{\mathrm{c}}$, at $0.532 \mu \mathrm{m}$. However, the transmittance method does not work in attenuation-limited clouds or when signal-to-noise ratio (SNR) is poor because sufficient lidar signal on the far side of the cloud (in this case below cloud) is required (Young, 1995; Immler and Schrems, 2002b). Therefore, this technique would likely be limited if it is applied to the CALIOP data, because of the signal attenuation effects in opaque cloud layers, and the effects of bright solar background signals during the daytime orbital segments. The backward iterative solution to the lidar equation is widely applied due to a stable and accurate solution (Klett, 1981). For the spaceborne lidar system CALIOP, however, backward solutions are often problematic because it is usually difficult to determine accurate, far-field boundary conditions with any confidence, especially under the conditions of reduced SNR encountered during daytime measurements (Young and Vaughan, 2009).

The Hybrid Extinction Retrieval Algorithm (HERA), based on a forward iterative method, has been developed to perform extinction coefficient retrievals for CALIOP data sets (Young et al., 2007; Young and Vaughan, 2009). Moreover, two crucial parameters, the lidar ratio, $S_{\mathrm{c}}$, and multiple scattering factors, $\eta$, for the lidar equation inversion are supplied by the Scene Classification Algorithm (SCA) (Liu et al., 2005; Omar et al., 2009). The cirrus cloud visible optical depth, $\delta_{\mathrm{c}}$, obtained from CALIOP level 2 cloud layer products may be derived as:

$$
\delta_{\mathrm{c}}=\int_{r_{\mathrm{b}}}^{r_{\mathrm{t}}} S_{\mathrm{c}} \beta_{\mathrm{c}}(r) d r
$$

where $r_{\mathrm{t}}$ and $r_{\mathrm{b}}$ are the cirrus cloud top and base heights.

\subsubsection{Depolarization and color ratio}

A layer-integrated volume depolarization ratio $\Delta^{\prime}$ and color ratio $\chi^{\prime}$ for clouds can be written (Platt et al., 1998; Vaughan et al., 2005) respectively as:

$$
\begin{gathered}
\Delta^{\prime}=\frac{\gamma_{\mathrm{c}, \perp}^{\prime}}{\gamma_{\mathrm{c}, \|}^{\prime}}, \\
\chi^{\prime}=\frac{\gamma_{\mathrm{c}, 1064}^{\prime}}{\gamma_{\mathrm{c}, 532}^{\prime}},
\end{gathered}
$$

where $\gamma_{c, \perp}^{\prime}$ and $\gamma_{c, \|}^{\prime}$ are the sum of the perpendicular and parallel attenuated backscatter at $0.532 \mu \mathrm{m}$ over the cloud depth, and $\gamma_{\mathrm{c}, 1064}^{\prime}$ and $\gamma_{\mathrm{c}, 532}^{\prime}$ are the similar sum of attenuated backscatter at 1.064 and $0.532 \mu \mathrm{m}$. 


\section{Results and discussion}

\subsection{Macrophysical properties}

Two years of CALIOP data permit an assessment of the monthly variability of cirrus cloud macrophysical properties over North China. We use the processed Level 2 cloud product at $5 \mathrm{~km}$ horizontal resolution. It is worth noting that in order to compare our results with the International Satellite Cloud Climatology Project (ISCCP) D2 global grid dataset data (Rossow and Schiffer, 1999), and reduce attenuation bias from the top-layer cirrus cloud, we only chose the top-layer cirrus cloud cases in CALIOP data for this investigation.

Figure 1a depicts the total number of CALIPSO instrument orbital passes in our research domain with cirrus deemed present (black bar) and number of cases without cirrus (white bar). Shown in Fig. 1b are monthly occurrence frequencies of orbital passes with cirrus observed, cirrus (equal to the ratio of number of top-layer cirrus clouds versus total number of profiles), and overlapping cirrus cloud layers. Due to what we believe is the influence of synoptic conditions and atmospheric circulation on midlatitude cirrus cloud formation and presence (Sassen and Campbell, 2001), we find a maximum frequency presented in June (37.2\%) and minimum value in December $(13.1 \%)$. The relatively higher coverage in summer is attributed not only to the relatively abundant upper-tropospheric water vapor introduced by regional convective activity influenced by the Western Tropical Pacific (Huang and Sun, 1992), but also the seasonal meridional displace- ment of sub-tropical cirrus bands (Sassen et al., 2008).

It is well-known that cloud overlapping information is of importance to climate models (Randall et al., 1989). Global occurrence frequencies of overlapping cloud layers approach $40 \%$, and vary from less than $10 \%$ over deserts and mountains to over $80 \%$ in tropical convective regions (Stephens et al., 2002). The square symbols in Fig. 1b are the monthly occurrence frequencies of overlapping cirrus cloud layers. Variability in the occurrence of overlapping cloud layers may reflect the irregular influence on local cloud formation of inertial gravity wave activity that is enhanced by the complex regional surface terrain (Lynch et al., 2002).

Displayed in Fig. 2 are comparisons of monthly mean values of cirrus cloud physical parameters (cloud base and top heights, corresponding temperatures, and geometric thickness) derived from the CALIOP data sets with those reported in the ISCCP D2 global grid data set from January 1983 to June 2006 over North China. Figure 2a shows the maximum monthly mean cirrus cloud top $(12.29 \mathrm{~km})$ and base $(10.82 \mathrm{~km})$ heights that are observed in August. Figure $2 \mathrm{~b}$ depicts monthly mean temperatures at the top, middle and base heights. The total mean cirrus top temperature $\left(-56.6^{\circ} \mathrm{C}\right)$ is slightly colder than the ISCCP value $\left(-53.8^{\circ} \mathrm{C}\right)$. Cloud top temperatures from CALIOP observations match well with ISCCP retrievals in the winter. However, in the other seasons, especially summer, they are considerably lower than those of ISCCP. We attribute this to the likelihood for CALIOP detecting optically thin, sporadic and cold cirrus clouds caused by regional convection. The higher sensitivities to cirrus cloud detection using the CALIOP in-
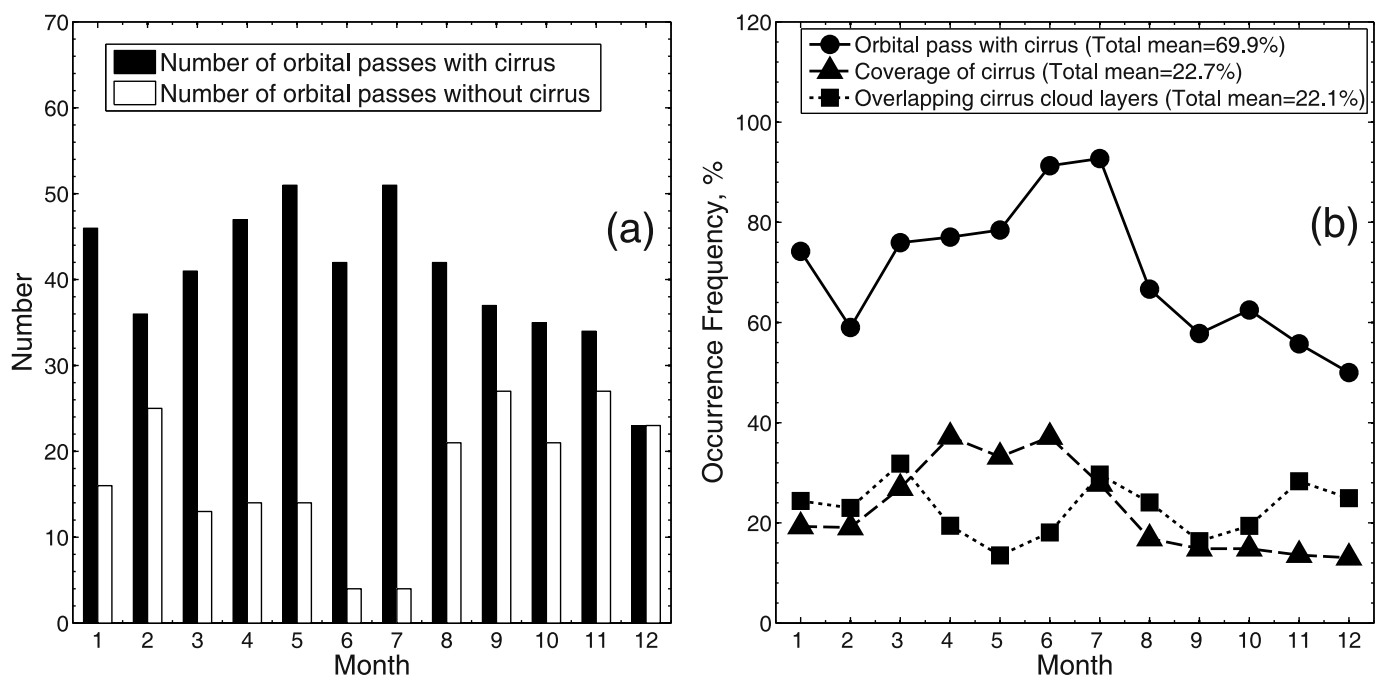

Fig. 1. (a) Monthly number of CALIPSO orbital passes within our research domain containing cirrus clouds (black bar) and those without cirrus (white bar). (b) Monthly occurrence frequencies of orbital pass with cirrus, coverage of cirrus, and overlapping cirrus cloud layers. 


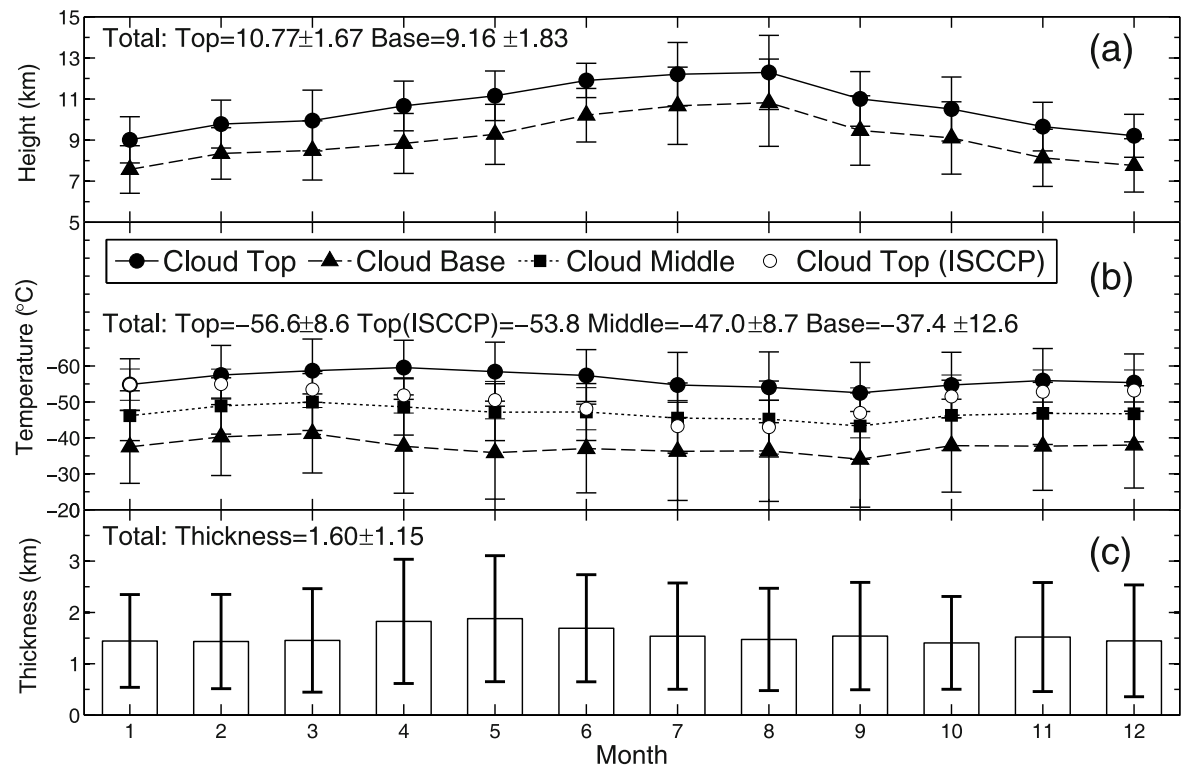

Fig. 2. (a) Monthly mean heights of cirrus cloud tops and base heights. (b) Corresponding monthly mean temperatures of cloud tops, middle cloud, and cloud base. The hollow circles represent the monthly mean cloud top temperatures from the ISCCP data sets over North China. (c) Monthly mean cloud layer thicknesses for cirrus. Total mean values for cirrus cloud properties are noted in every figure.

strument is advantageous in this regard compared to the ISCCP (Weisz et al., 2007). Monthly mean cirrus cloud layer thicknesses are shown in Fig. 2c. The total mean value of $1.60 \mathrm{~km}$ is smaller than that found in a previous mid-latitude study of cirrus clouds from Western North America (2.79 $\pm 1.38 \mathrm{~km})$ by Sassen and Comstock (2001). This finding will be discussed in further context below, as we believe there is some ambiguity present.

Shown in Fig. 3, are probability density functions (PDF) for the previously described cirrus cloud macrophysical parameters from Fig. 2. Figure 3a shows the PDF for cloud tops and base heights. The cirrus cloud thickness distribution (Fig. 3b) centers near $1.5 \mathrm{~km}$. In Fig. 3c, it is the PDF for cirrus cloud tops and base temperature. Although cirrus cloud top temperatures from both CALIOP and the ISCCP center around $-55^{\circ} \mathrm{C}$, the CALIOP data contain a greater number of cases with temperatures lower than $-50^{\circ} \mathrm{C}$ and higher than $-80^{\circ} \mathrm{C}$.

\subsection{Frequency Distribution}

Figure 4 shows the probability distribution functions (PDF) of cirrus cloud infrared emittance, $\varepsilon_{\mathrm{a}}$, at $10.6 \mu \mathrm{m}$ in 0.05 interval, optical depth, $\delta_{\mathrm{c}}$, at 0.532 $\mu \mathrm{m}$ in 0.1 interval, integrated volume depolarization ratio, $\Delta^{\prime}$, in 0.05 interval, and integrated color ratio, $\chi^{\prime}$, in 0.05 interval. The dashed line in Fig. 4d represents the results of June to August of 2006. Total mean values for cirrus cloud properties are noted in every figure.

Figure 4a shows the PDF of cirrus cloud infrared emittance. Infrared-optical and solar-albedo properties of cirrus clouds combine to determine their sum radiative effect (Liou, 1986). Multi-layered clouds and a lack of background infrared radiance can cause the retrieval, identified in section 2.2.1, for cirrus cloud infrared optical properties to fail. In view of these limitations, the results described in this section represent fewer sample cases than those reported for other cirrus cloud properties. The distribution of occurrence frequencies of infrared emittance is similar to the results from Sassen and Comstock (2001). But, they differ from the Platt et al. (1998) equatorial study. This is attributed to the relatively higher occurrence frequency of the physically thick cirrus in the equatorial region, which is often associated with deep convective activities in the Intertropical Convergence Zone (ITCZ) (Mace et al., 2006).

Figure $4 \mathrm{~b}$ exhibits a PDF histogram of 0.1 intervals of cirrus visible optical depth. Although our results contain more samples with optical depth $<0.2$ than that derived by Vaughan et al. (2008) using CALIOP and Cloud Physical Lidar (CPL) measurements, the bulk of our observations coincide with values lower than 1, which resembles that from Vaughan et al. (2008). A total mean value of optical depth of $0.41 \pm 0.68$ is consistent with the mean result of 0.42 

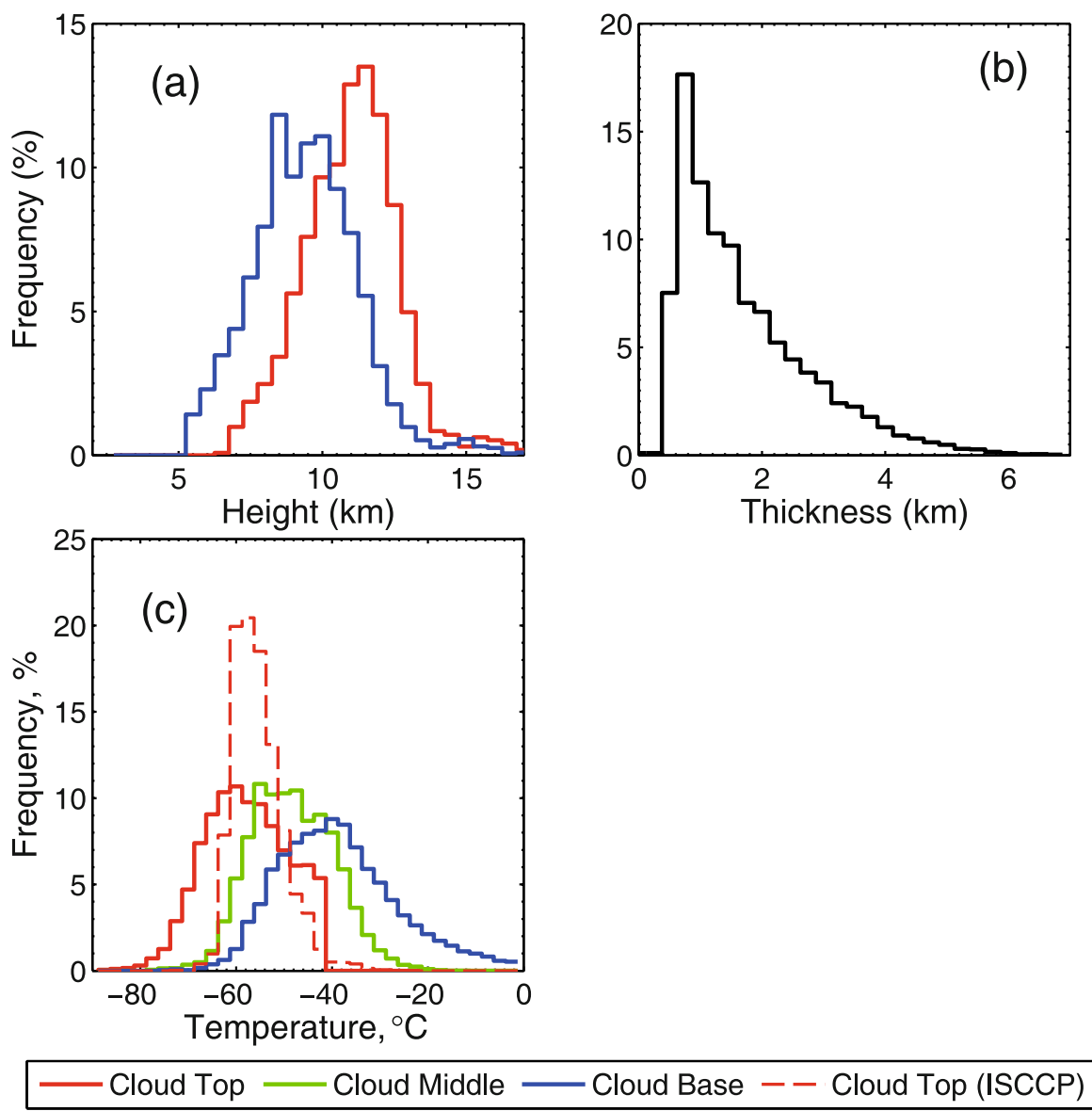

Fig. 3. Probability distribution functions (PDF) of (a) cirrus cloud-tops and base heights $\left(0.5 \mathrm{~km}\right.$ interval) and (b) thickness $\left(0.25 \mathrm{~km}\right.$ interval), (c) temperatures $\left(2.5^{\circ} \mathrm{C}\right.$ interval). The red dashed line represents the PDF of cloud top temperature from the ISCCP data set. The marks in the textbox represent the results for (a) and (c).

from Vaughan et al. (2008). However, these results are significantly lower than the value, $0.751 \pm 0.91$, from ground-based lidar reported by Sassen and Comstock (2001). In addition to the different attenuated effect, a greater frequency of optically thin cirrus clouds over North China induces the relatively lower value.

In addition, Table 1 shows a comparison of frequency distributions of different cirrus categories between this work and Sassen and Campbell (2001) that are divided on the basis of ranges of $\delta_{\mathrm{c}}$ versus visual appearance (Sassen and Cho, 1992). We find a frequency of subvisible cirrus $\left(\delta_{\mathrm{c}} \leqslant 0.03\right)$ of $30.26 \%$ is obviously higher than $17 \%$ reported by (Sassen and Campbell, 2001). A nominal cloud scene where total optical depth exceeds approximately 3.0 will cause the laser source pulse to become attenuated before the full profile may be sampled Sassen and Cho (1992).

Figures $4 \mathrm{c}$ and $4 \mathrm{~d}$ exhibit the PDFs of cirrus cloud

Table 1. Frequency distributions for cirrus categories from this study based on cirrus visible optical depth, $\delta_{\mathrm{c}}$, (Sassen and Cho, 1992) and those from Sassen and Campbell (2001).

\begin{tabular}{llll}
\hline Cirrus category & $\delta_{\mathrm{c}}$ range & Frequency & Sassen and Campbell $(2001)$ \\
\hline Very thin cirrus & $\delta_{\mathrm{c}} \leqslant 0.03$ & $30.26 \%$ & $17 \%$ \\
Thin cirrus & $0.03<\delta_{\mathrm{c}} \leqslant 0.3$ & $34.59 \%$ & $34 \%$ \\
Opaque cirrus & $0.3<\delta_{\mathrm{c}} \leqslant 3$ or 1 & $21.54 \%\left(\delta_{\mathrm{c}} \leqslant 1\right)$ & $34 \%\left(\delta_{\mathrm{c}} \leqslant 3\right)$ \\
Range-limited & - & $13.61 \%\left(\delta_{\mathrm{c}}>1\right)$ & $12 \%$ \\
Null observation & - & - & $3 \%$ \\
\hline
\end{tabular}



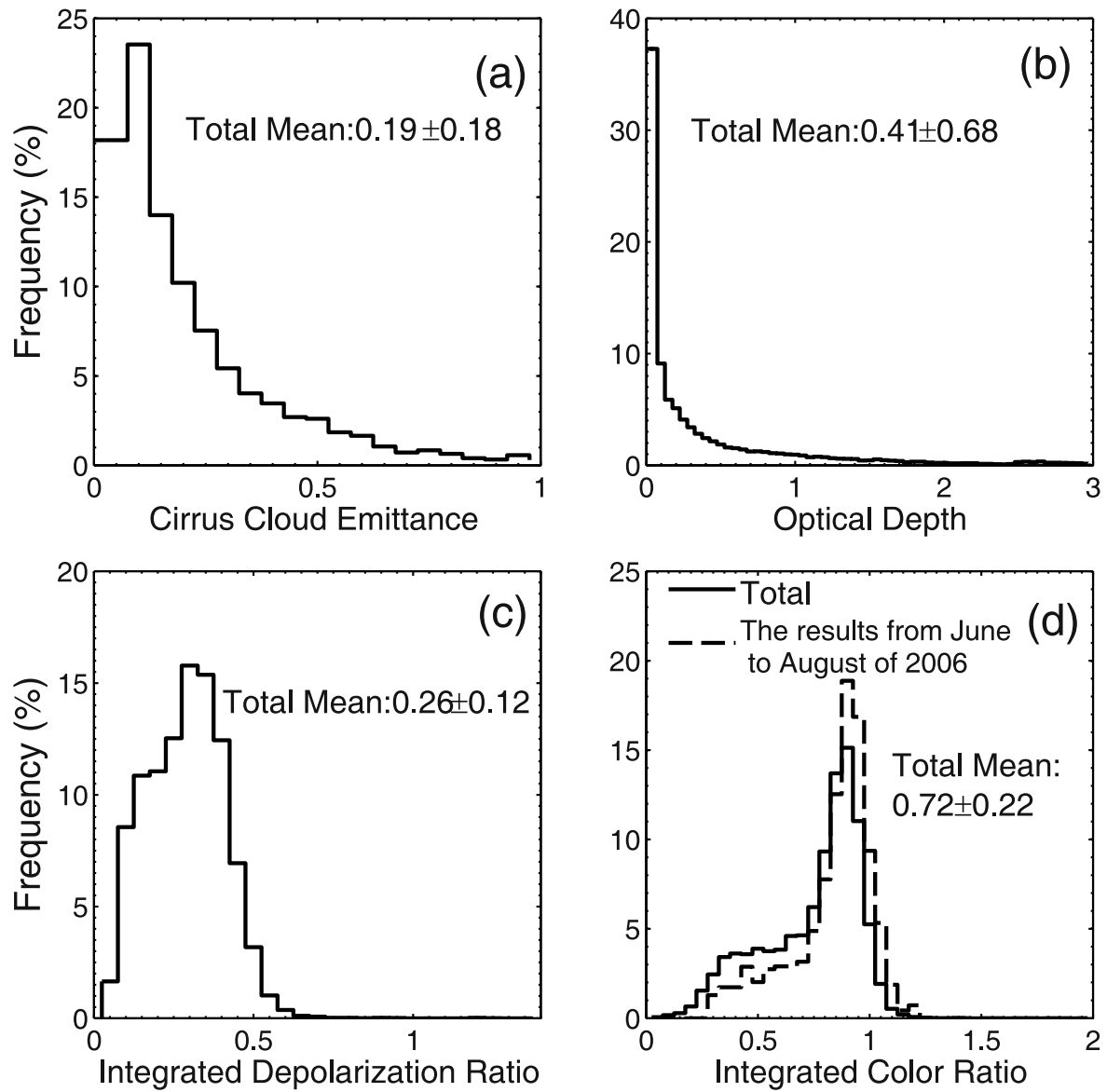

Fig. 4. Probability distribution functions (PDF) of cirrus cloud (a) infrared emittance, $\varepsilon_{\mathrm{a}}$, at $10.6 \mu \mathrm{m}$ in 0.05 intervas, (b) optical depth, $\delta_{\mathrm{c}}$, at $0.532 \mu \mathrm{m}$ in 0.1 intervals (c) integrated volume depolarization ratio, $\Delta^{\prime}$, in 0.05 intervals, and (d) integrated color ratio, $\chi^{\prime}$, in 0.05 intervals. The dashed line in Fig. $4 \mathrm{~d}$ represents the results of June to August of 2006. Total mean values for cirrus cloud properties are noted in every figure.

integrated volume depolarization ratio $\Delta^{\prime}$ and color ratio $\chi^{\prime}$. These measurements, when considered in tandem, depict sensitivity to particle shape, orientation and size in the scattering layer (Noel et al., 2004). Thus, they may be considered when distinguishing the type of scatterer, particularly ice-phase clouds that regularly depolarize incident laser energy versus liquidphase clouds that do not (Hu et al., 2007; Sassen, 1991). These macrophysical properties can also be related to inherent parameters such as mid-cloud temperature $T_{\text {mid }}$ and integrated attenuated backscatter (Liou et al., 1998; Sassen and Campbell, 2001; Tao et al., 2008).

Mean $\Delta^{\prime}$ and $\chi^{\prime}$ values derived from this CALIOP data subset are $0.26 \pm 0.12$ and $0.72 \pm 0.22$, respectively. The majority of $\Delta^{\prime}$ are lower than 0.6 , though most often in the range of $0.2-0.8$ (Sassen, 1991). The color ratio values distribute around 0.85 from Fig. $4 d$. How- ever, we speculate that there may be some inherent offset present in these results, since the values should nominally center closer to 1.0 from theoretical simulation of Mie scatterers (Liu et al., 2004). In addition to the molecular signal neglected in the $\chi^{\prime}$ calculation, the attenuation effect and potential offsets in the calibration of the lidar system constant in the $1.064 \mu \mathrm{m}$ channel can also impact on $\chi^{\prime}$. The dashed line in Fig. $4 d$ represents the PDF result from June to August of 2006. There are more data points from this result that focus around 0.85 than the total results plotted with a solid line, indicating attenuation at the $1.064 \mu \mathrm{m}$ channel.

\subsection{Dependence of cirrus cloud properties}

Figure 5 shows the relationships between mid-cloud temperature, $T_{\text {mid }}$, in $10^{\circ} \mathrm{C}$ intervals and cirrus cloud layer thickness, infrared emittance, optical depth at 

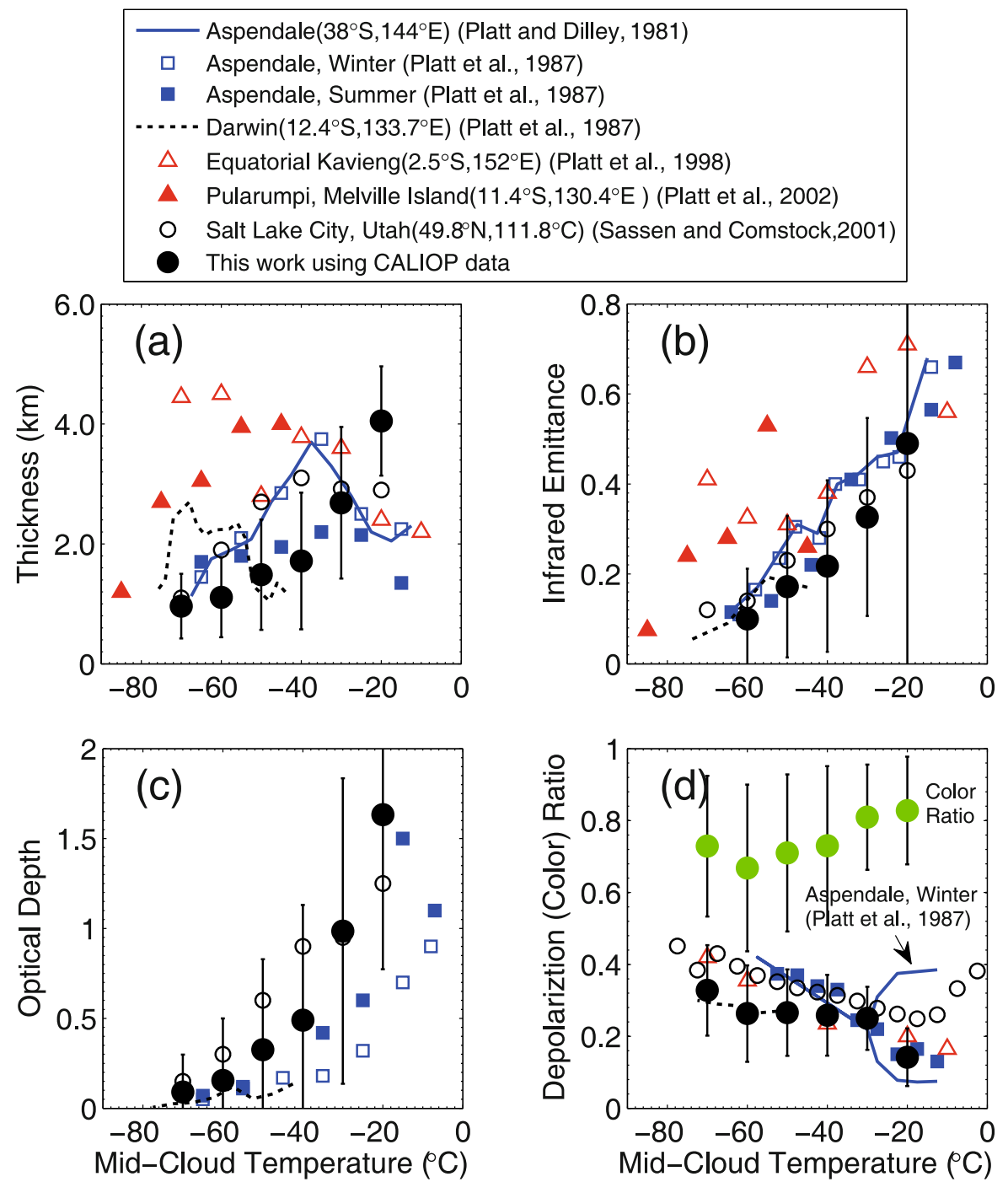

Fig. 5. Dependence of cirrus cloud layer (a) thickness, (b) infrared emittance, $\varepsilon_{\mathrm{a}}$, (c) optical depth at $0.532 \mu \mathrm{m}, \delta_{\mathrm{c}}$, and (d) integrated depolarization, $\Delta^{\prime}$, and color ratios, $\chi^{\prime}$, on mid-cloud temperature, $T_{\text {mid }}$, in $10^{\circ} \mathrm{C}$ intervals from this study and others. The black solid circles are the results of this work, and the other marks are derived from previous studies (see inset). In Fig. 5d, the green solid circles and blue solid line represent the results of color ratio and depolarization ratio observed in Aspendale in winter (Platt et al., 1987).

$0.532 \mu \mathrm{m}$, integrated depolarization, and color ratios.

Shown in Fig. 5a is the relationship between cirrus cloud thicknesses and $T_{\text {mid }}$. The results from the North China region are compared to previous cirrus cloud studies (see inset). The comparison yields differences between our work and results derived at tropical regions (Platt et al., 1987, 1998, 2002a), particularly those near the equator from Platt et al. (1998). However, despite the earlier disagreement noted between mean cirrus cloud layer depths compared with ground-based mid-latitude lidar studies, the general trend in the plot mostly shows agreement with results reported by Platt and Dilley (1981), Platt et al. (1987), and Sassen and Comstock (2001). Some disagreement near $-20^{\circ} \mathrm{C}$ may be the result of a sampling bias from mixed-phase clouds and strongly attenuating altostratus (Sassen and Comstock, 2001). The influence of such cases is harder to determine from CALIOP data sets compared to those collected at the ground from the difference in viewing geometry. However, we are confident that the second cirrus identification threshold, which relies on a maximum cloud top temperature of $-40^{\circ} \mathrm{C}$, helps to eliminate many of the data points at warmer temperatures. 

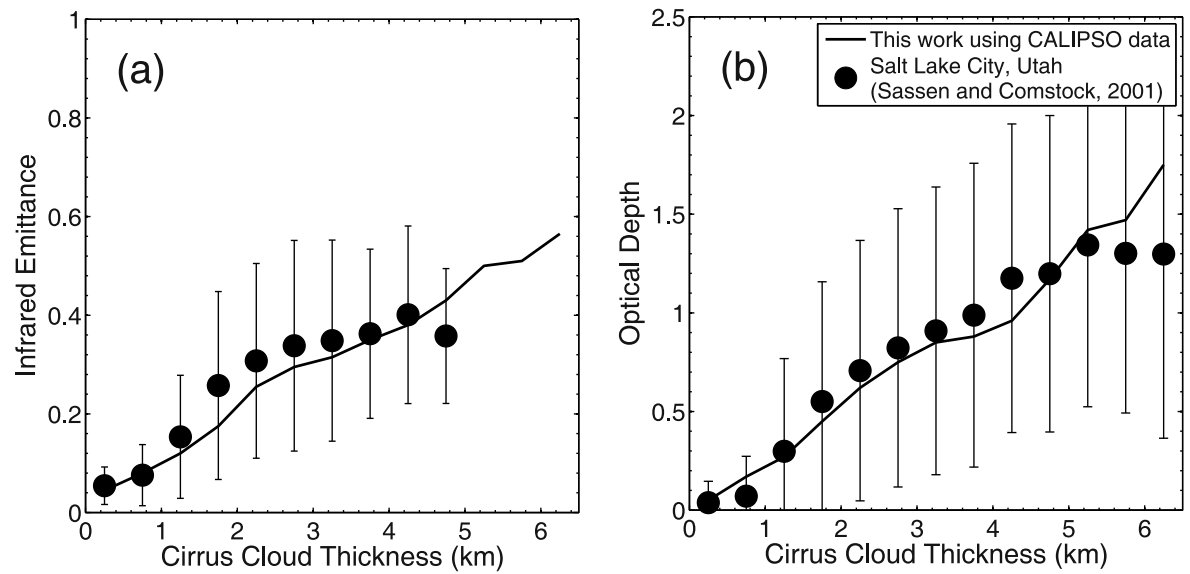

Fig. 6. Dependence of cirrus cloud (a) infrared emittance, $\varepsilon_{\mathrm{a}}$, at $10.6 \mu \mathrm{m}$, and (b) optical depth at $0.532 \mu \mathrm{m}, \delta_{c}$, on cirrus cloud thickness in $0.5 \mathrm{~km}$ intervals. The black solid line represents the results derived from Sassen and Comstock (2001).

The dependence of cirrus cloud infrared emittance on $T_{\text {mid }}$ is depicted in Fig. 5b. Despite the difference in wavelengths of the infrared radiometer in each separate experiment, the trend in $\varepsilon_{\mathrm{a}}$ is similar to our results shown in Fig. $5 \mathrm{~b}$, and it is consistent with those from other mid-latitude regions (Platt and Dilley, 1981; Platt et al., 1987; Sassen and Comstock, 2001). The shortage of cirrus cases around $-70^{\circ} \mathrm{C}$ is likely to be a result of a lower sensitivity to optically thin cirrus using CALIOP when compared to groundbased instruments.

The relationship between mean $\delta_{\mathrm{c}}$ and $T_{\text {mid }}$ is displayed in Fig. 5c. This figure depicts the corresponding estimation of $\delta_{\mathrm{c}}$, when compared with similar findings by Sassen and Comstock (2001). The weakly increasing trend of $\delta_{\mathrm{c}}$ from $-70^{\circ} \mathrm{C}$ to $-40^{\circ} \mathrm{C}$ may represent an artifact of instrument sampling limits for optically thick clouds.

Figures $5 \mathrm{~d}$ depicts the relationships between $\Delta^{\prime}$ and $\chi^{\prime}$ with $T_{\text {mid }}$. Despite Fig. 5 d depicting a decreasing trend of $\Delta^{\prime}$ with $T_{\text {mid }}$ that is similar to results from other mid-latitude regions, differences exist. We believe this geographical difference in the depolarization ratio in cirrus reflects dissimilarities in the dominant generating mechanism, and in the nature and source of cloud nuclei that influence the nucleation temperature and, therefore, the shape of the ice crystals (Sassen and Benson, 2001). Figure 5d exhibits an unremarkable dependence of $\chi^{\prime}$ on $T_{\text {mid }}$.

In light of the dependences of $\varepsilon_{\mathrm{a}}$ and $\delta_{\mathrm{c}}$ on $T_{\text {mid }}$, the similar dependences of $\varepsilon_{\mathrm{a}}$ and $\delta_{\mathrm{c}}$ on cirrus cloud layer thickness are depicted in Fig. 6. The black solid line represents the results derived from Sassen and Comstock (2001).

In Fig. 6a, a gradual increasing trend is seen, similar to that found by Sassen and Comstock (2001).
However, a slight decreasing trend near the $5 \mathrm{~km}$ thickness may indicate a relatively lower penetrability of CALIOP compared with ground-based lidars. Besides a similar finding of $\delta_{c}$, when compared with that derived by Sassen and Comstock (2001) can be found in Fig. 6b.

Finally, we have substituted the integrated attenuated coefficient, $\gamma_{\mathrm{t}}$, at $0.532 \mu \mathrm{m}$ for optical depth to investigate its dependence on attenuated or multiple scattering properties. The purpose of this is to diminish the effects of assumptive parameters on the lidar inversion (Sasano et al., 1985). Figure 7 shows the dependences of integrated depolarization ratio, $\Delta^{\prime}$, and color ratio, $\chi^{\prime}$, in 0.02 intervals of integrated attenuated backscatter, $\gamma_{\mathrm{t}}$, at $0.532 \mu \mathrm{m}$. A decreasing trend

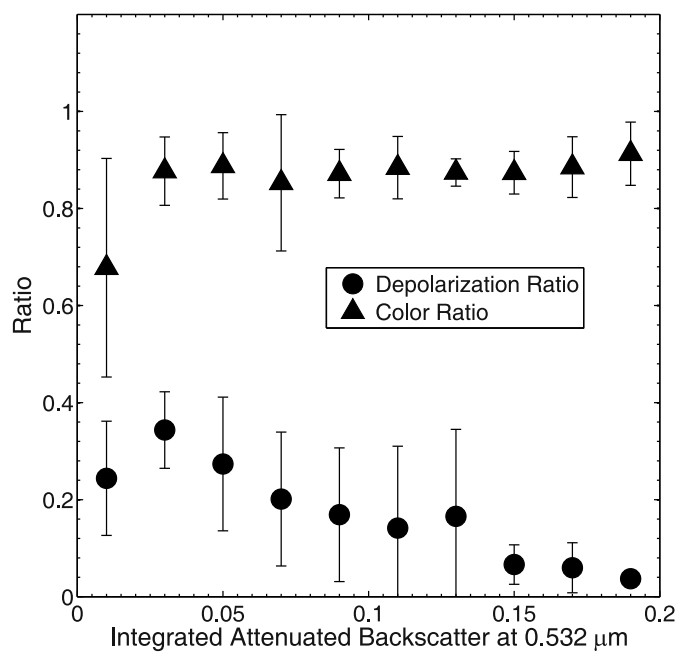

Fig. 7. Dependence of integrated depolarization ratio, $\Delta^{\prime}$, and color ratio, $\chi^{\prime}$, on integrated attenuated backscatter, $\gamma_{\mathrm{t}}$, at $0.532 \mu \mathrm{m}$ in 0.02 intervals. 
of $\Delta^{\prime}$ compared with $\gamma_{\mathrm{t}}$ are shown in Fig. 7. We speculate that the relatively low values of $\Delta^{\prime}$ represents the presence in our cloud sample of horizontally-oriented ice particles, embedded supercooled water droplets, as well as some multiple scattering effects that groundbased remote sensors, with attentive instrument operators, may seek to avoid (Sassen, 1991; Sassen and Benson, 2001). Nevertheless, both Fig. 5d and 7 indicate that $\chi^{\prime}$ shows less dependence on $T_{\text {mid }}$ or $\gamma_{\mathrm{t}}$. Tao et al. (2008) also have demonstrated that $\chi^{\prime}$ is relatively invariable with height in well-developed and mature cirrus cloud layers.

\section{Summary}

This study examines two years of continuous Cloud-Aerosol Lidar with Orthogonal Polarization (CALIOP) data to study cirrus cloud physical properties over North China from June 2006 to May 2008. In the bulk of our sample cases, the $0.532 \mu \mathrm{m}$ cloud optical depth does not exceed 1.0. Though our macrophysical findings generally resemble those reported from previous ground-based mid-latitude studies of cirrus clouds, we can not rule out some systematic influence from a lack of optically thick clouds in our sample.

We summarize our primary results as follows:

(1) A simple approach averaging the upward nadirviewing infrared radiances in the cloudless regions as the background infrared radiances have been used to calculate infrared optical properties.

(2) Our analysis of cloud occurrence frequencies and physical properties shows monthly trends that follow seasonal cycles. Exceptions to this include cirrus cloud layer thicknesses and the occurrence and frequency of overlapping cirrus cloud layer structures. We attribute the latter differences to the prevalent dynamic generating mechanisms and regional terrain influences in the form of inertial gravity waves. Compared to passive satellite-based measurement approaches (ISCCP), space-borne lidar may be used to derive more vertical information on cirrus clouds. The CALIOP instrument sensitivity to cirrus allows for better discrimination of high and optically thin cirrus layer heights. Due to viewing geometry compared with ground-based measurements, we anticipate that mid-level mixed-phase clouds and strongly attenuating altostratus should not prominently effect the identification of cirrus in the CALIOP data. Therefore, the mean cloud layer thickness at $-20^{\circ} \mathrm{C}$ is higher than ground observations.

(3) The attenuation effects of optically thick cirrus leads to $0.532 \mu \mathrm{m}$ optical depth retrievals, computed by lidar signal inversions, that are lower than established climatological means derived from ground- based lidars in other mid-latitude regions. Although this finding is not generally unexpected, due to potential differences in dominant synoptic and regional convective dynamics, statistical analysis shows that most of our sample cases (about 87.4\%) do not exceed 1.0.

(4) Trends for increasing CALIOP-retrieved infrared emittance values with mid-cloud temperatures and cirrus cloud layer thicknesses correspond well with similar measurements made from ground-based lidars at mid-latitude sites. However, a potentially lower sensitivity to subvisible cirrus leads to the lack of cirrus cases around $-70^{\circ} \mathrm{C}$ when compared to ground measurements.

(5) The dependence of $\Delta^{\prime}$ on mid-cloud temperature and integrated attenuated backscatter are statistically significant, but for color ratios, it shows a weaker dependence. The presence of horizontally oriented ice particles, supercooled water in mixed-cloud layers, and the increased effects of multiple scattering may bias our sample causing relatively low values of depolarization ratio when compared to previous studies. The dissimilarities in dominant cloud generating mechanisms and the nature and source of cloud nuclei is also expected to yield geographical differences in cirrus cloud microphysical properties and, therefore, depolarization ratios.

Acknowledgements. The authors thank Gordon Labow (NASA Goddard) who provided many helpful ideas. The authors also thank Prof. XIA Xiangao who also provided many worthwhile suggestions. Author J. C. thanks Dr. Jeffrey Reid (Naval Research Laboratory) for his support. CALIOP and ISCCP data sets are both freely disseminated by the NASA Langley Research Center Atmospheric Sciences Data Center, and we acknowledge their assistance. This research is supported by the National Natural Science Foundation of China (Grant No. 40875084) and National Natural Science Foundation for Youth Science Foundation of China (Grant No. 40705012).

\section{REFERENCES}

Baker, M. B., 1997: Cloud microphysics and climate. Science, 267, 1072-1078.

Chen, W. N., C. W. Chiang, and J. B. Nee, 2002: Lidar ratio and depolarization ratio for cirrus clouds. Appl. Opt., 41, 6470-6476.

Chomette, O., and Coauthors, 2003: Retrieval of cloud emissivity and particle size frame of the CALIPSO mission. IEEE International Geoscience and Remote Sensing Symposium, Toulouse, France, 1520-1522.

Dowling, D. R., and L. F. Radke, 1990: A summary of the physical properties of cirrus clouds. J. Appl. Meteor., 29, 970-978.

Heymsfield, A. J., 1975: Cirrus uncinus generating cells 
and the evolution of cirriform clouds. Part I: Aircraft observations of the growth of the ice phase. J. Atmos. Sci., 32, 799-807.

Huang, R. H., and F. Y. Sun, 1992: Impacts of the Tropical Western Pacific on the East-Asian summer monsoon. J. Meteor. Soc. Japan, 70, 243-256.

$\mathrm{Hu}, \mathrm{Y}$., and Coauthors, 2007: The depolarizationattenuated backscatter relation: CALIPSO lidar measurements vs. theory. Optics Express, 15, 53275332.

Hu, Y., and Coauthors, 2009: CALIPSO/CALIOP cloud phase discrimination algorithm. J. Atmos. Oceanic Technol., 26, 2293-2309.

Immler, F., and O. Schrems, 2002a: LIDAR measurements of cirrus clouds in the northern and southern midlatitudes during INCA $\left(55^{\circ} \mathrm{N}, 53^{\circ} \mathrm{S}\right)$ : A comparative study. Geophys. Res. Lett., 29, 1809, doi: 10.1029/2002GL015077.

Immler, F., and O. Schrems, 2002b: Determination of tropical cirrus properties by simultaneous LIDAR and radiosonde measurements. Geophys. Res. Lett., 29, 2090, doi: 10.1029/2002GL015076.

IPCC, 2007: Historical overview of climate change science. Climate Change 200\%: The Physical Science Basis. Contribution of Working Group I to the Fourth Assessment Report of the Intergovernmental Panel on Climate Change, Solomon et al., Eds., Cambridge University Press, Cambridge, United Kingdom and New York, NY, USA., 93-127.

Kahn, B. H., and Coauthors, 2008: Cloud type comparisons of AIRS, CloudSat, and CALIPSO cloud height and amount. Atmos. Chem. Phys., 8, 1231-1248.

Kim, S.-W., S. Berthier, J.-C. Raut, P. Chazette, F. Dulac, and S.-C. Yoon, 2008: Validation of aerosol and cloud layer structures from the space-borne lidar CALIOP using a ground-based lidar in Seoul, Korea. Atmos. Chem. Phys., 8, 3705-3720.

Klett, J. D., 1981: Stable analytical inversion solution for processing lidar returns. Appl. Opt., 20, 211-220.

Liou, K., P. Yang, Y. Takano, K. Sassen, T. Charlock, and W. Arnott, 1998: On the radiative properties of contrail cirrus. Geophys. Res. Lett., 25, 1161-1164.

Liou, K. N., 1986: Influence of cirrus clouds on weather and climate processes: A global perspective. Mon. Wea. Rev., 114, 1167-1199.

Liu, Z., and Coauthors, 2004: Use of probability distribution functions for discriminating between cloud and aerosol in lidar backscatter data. J. Geophys. Res., 109, D15202, doi: 10.1029/2004JD004732.

Liu, Z., A. H. Omar, Y. Hu, M. A. Vaughan, and D. M. Winker, 2005: CALIOP algorithm theoretical basis document. Part 3: Scene classification algorithms. NASA CALIPSO Algorithm Theoretical Basis Documents, 56pp.

Liu, Z., and Coauthors, 2009: The CALIPSO Lidar Cloud and Aerosol Discrimination: Version 2 Algorithm and Initial Assessment of Performance. J. Atmos. Oceanic Technol., 26, 1214-1228.

Lynch, D. K., K. Sassen, D. O. C. Starr, and G. Stephens,
2002: Cirrus. Oxford University Press, New York, 480pp.

Mace, G. G., S. Benson, and E. Vernon, 2006: Cirrus clouds and the large-scale atmospheric state: Relationships revealed by six years of ground-based data. J. Climate, 19, 3257-3278.

Martin, C., R. Platt, and Harshvardhan, 1988: Temperature dependence of cirrus extinction: Implications for climate feedback. J. Geophys. Res., 93, 1105111058.

McGill, M. J., M. A. Vaughan, C. R. Trepte, W. D. Hart, D. L. Hlavka, D. M. Winker, and R. Kuehn, 2007: Airborne validation of spatial properties measured by the CALIPSO lidar. J. Geophys. Res., 112, D20201, doi: 10.1029/2007JD008768.

Noel, V., D. M. Winker, M. McGill, and P. Lawson, 2004: Classification of particle shapes from lidar depolarization ratio in convective ice clouds compared to in situ observations during CRYSTALFACE. J. Geophys. Res., 109, D24213, doi: 10.1029/2004JD004883.

Omar, A., and Coauthors, 2009: The CALIPSO automated aerosol classification and lidar ratio selection algorithm. J. Atmos. Oceanic. Technol., 26, 19942014.

Platt, C. M. R., 1973: Lidar and radiometric observations of cirrus clouds. J. Atmos. Sci., 30, 1191-1204.

Platt, C. M. R., 1979: Remote sounding of high clouds: I. calculation of visible and infrared optical properties from lidar and radiometer measurements. J. Appl. Meteor., 18, 1130-1143.

Platt, C. M. R., and A. C. Dilley, 1979: Remote sounding of high clouds: II. Emissivity of cirrostratus. J. Appl. Meteor., 18, 1144-1150.

Platt, C. M. R., and Dilley, A. C. 1981: Remote sounding of high clouds. IV: observed temperature variations in cirrus optical properties. J. Atmos. Sci., 38, 1069 1082.

Platt, C. M. R., and S. A. Young, 2004: Cloud backscatter phase function and emittance of low and midlevel clouds from LIRAD-type measurements from CALIPSO. ILRC 2004, G.. Pappalardo and A. Amodeo, Matera, Eds., Italy, 945-947.

Platt, C. M. R., J. C. Scott, and A. C. Dilley, 1987: Remote sounding of high clouds. Part VI: Optical properties of midlatitude and tropical cirrus. J. Atmos. Sci., 44, 729-747.

Platt, C. M. R., S. A. Young, P. J. Manson, G. R. Patterson, S. C. Marsden, R. T. Austin, and J. H. Churnside, 1998: The optical properties of equatorial cirrus from observations in the ARM Pilot radiation observation experiment. J. Atmos. Sci., 55, 1977-1996.

Platt, C. M. R., S. A. Young, R. T. Austin, G. R. Patterson, D. L. Mitchell, and S. D. Miller, 2002a: LIRAD observations of tropical cirrus clouds in MCTEX. Part I: Optical properties and detection of small particles in cold cirrus. J. Atmos. Sci., 59, 3145-3162.

Platt, C. M. R., R. T. Austin, S. A. Young, and A. J. Heymsfield, 2002b: LIRAD observations of tropical 
cirrus clouds in MCTEX. Part II: optical properties and base cooling in dissipating storm anvil clouds. $J$. Atmos. Sci., 59, 3163-3177.

Randall, D. A., Harshvardhan, D. A. Dazlich, and T. G. Corsetti, 1989: Interactions among radiation, convection, and large-scale dynamics in a general circulation model. J. Atmos. Sci., 46, 1943-1970.

Rossow, W. B., and R. A. Schiffer, 1999: Advances in understanding clouds from ISCCP. Bull. Amer. Meteor. Soc., 80, 2261-2286.

Sasano, Y., E. V. Browell, and S. Ismail, 1985: Error caused by using a constant extinction /backscattering ratio in the lidar solution. Appl. Opt., 24, 39293932.

Sassen, K., 1991: The polarization lidar technique for cloud research: A review and current assessment. Bull. Amer. Meteorol. Soc., 72, 1848-1866.

Sassen, K., and B. S. Cho, 1992: Subvisual-thin cirrus lidar dataset for satellite verification and climatological research. J. Appl. Meteor., 31, 1275-1285.

Sassen, K., and S. Benson, 2001: A midlatitude cirrus cloud climatology from the facility for atmospheric remote sensing. Part II: Microphysical properties derived from lidar depolarization. J. Atmos. Sci., 58, 2103-2112.

Sassen, K., and J. M. Comstock, 2001: A midlatitude cirrus cloud climatology from the facility for atmospheric remote sensing. Part III: Radiative properties. J. Atmos. Sci., 58, 2113-2127.

Sassen, K., and J. R. Campbell, 2001: A midlatitude cirrus cloud climatology from the facility for atmospheric remote sensing. Part I: Macrophysical and synoptic properties. J. Atmos. Sci., 58, 481-496.

Sassen, K., and Z. Wang, 2008: Classifying clouds around the globe with the CloudSat radar: 1-year of results. Geophys. Res. Lett., 35, 1-5.

Sassen, K., M. Griffin, and G. C. Dood, 1989: Optical scattering and microphysical properties of subvisual cirrus clouds, and climatic implications. J. Appl. $\mathrm{Me}$ teor., 28, 91-98.

Sassen, K., Z. Wang, and D. Liu, 2008: Global distribution of cirrus clouds from CloudSat/Cloud-Aerosol Lidar and Infrared Pathfinder Satellite Observations (CALIPSO) measurements. J. Geophys. Res., 113, D00A12, doi: 10.1029/2008JD009972,

Stephens, G. L., S.-C. Tsay, W. S. Stackhouse Jr., and P. J. Flatau, 1990: The relevance of the microphysical and radiative properties of cirrus clouds to climate and climatic feedback. J. Atmos. Sci., 47, 1742-1754.

Stephens, G. L., D. G. Vane, R. J. Boain, G. G. Mace, and K. Sassen, 2002: The CloudSat mission and the A-Train: A new dimension of space-based observations of clouds and precipitation. Bull. Amer. Meteor. Soc., 83, 1771-1790.

Takano, Y., and K. N. Liou, 1989a: Solar radiative transfer in cirrus clouds. Part I: Single-scattering and optical properties of hexagonal ice crystals. J. Atmos.
Sci., 46, 3-19.

Takano, Y., and K. N. Liou, 1989b: Solar radiative transfer in cirrus clouds. Part II: Theory and computation of multiple scattering in an anisotropic medium. $J$. Atmos. Sci., 46, 20-36.

Tao, Z., M. P. McCormick, D. Wu, Z. Liu, and M. A. Vaughan, 2008: Measurements of cirrus cloud backscatter color ratio with a two-wavelength lidar. Appl. Opt., 47, 1478-1485.

Vaughan, M., R. Kuehn, S. Young, M. McGill, Z. Liu, and Y. Hu, 2008: Validating cirrus cloud optical properties retrieved by CALIPSO. ILRC 2008, Boulder, $\mathrm{CO}, \mathrm{USA}$.

Vaughan, M., and Coauthors, 2009: Fully automated detection of cloud and aerosol layers in the CALIPSO lidar measurements. J. Atmos. Oceanic Technol., 26, 2034-2050.

Weisz, E., J. Li, W. P. Menzel, A. K. Heidinger, B. H. Kahn, and C. Y. Liu, 2007: Comparison of AIRS, MODIS, CloudSat and CALIPSO cloud top height retrievals. Geophys. Res. Lett., 34, 1-5.

Wielicki, B. A., E. F. Harrison, R. D. Cess, M. D. King, and D. A. Randall, 1995: Mission to Planet Earth: Role of clouds and radiation in climate. Bull. Amer. Meteor. Soc., 76, 2125-2153.

Winker, D., and C. Trepte, 1998: Laminar cirrus observed near the tropical tropopause by LITE. Geophys. Res. Lett., 25, 3351-3354.

Winker, D. M., J. Pelon, and M. P. McCormick, 2003: The CALIPSO mission: Spaceborne lidar for observation of aerosols and clouds. Proc. SPIE Int. Soc. Opt. Eng., 4893, 1-11.

Winker, D. M., W. Hunt, and M. McGill, 2007: Initial performance assessment of CALIOP. Geophys. Res. Lett., 34, L19803, doi: 10.1029/2007GL030135.

Winker, D. M. and Coauthors, 2009: Overview of the CALIPSO mission and CALIOP data processing algorithms. J. Atmos. Oceanic Technol., 26, 23102323.

Wylie, D. P., and W. P. Menzel, 1999: Eight years of global high cloud statistics using HIRS. J. Climate, 12, 170-184.

Wylie, D. P., W. P. Menzel, H. M. Woolf, and K. I. Strabala, 1994: Four years of global cirrus cloud statistics using HIRS. J. Climate, 7, 1972-1986.

Young, S. A., 1995: Analysis of lidar backscatter profiles in optically thin clouds. Appl. Opt., 34, 7019-7031.

Young, S. A., M. A. Vaughan, Y. Hu, and R. E. Kuehn, 2007: CALIOP algorithm theoretical basis document, Part 4: Extinction retrieval and particle property algorithms. NASA CALIPSO Algorithm Theoretical Basis Documents, 63pp.

Young, S. A., and M. A. Vaughan, 2009: The retrieval of profiles of particulate extinction from Cloud Aerosol Lidar Infrared Pathfinder Satellite Observations (CALIPSO) data: Algorithm description. $J$. Atmos. Oceanic Technol., 26, 1105-1119. 